\title{
Some Biological Aspects and Stock Status of Goldlined Seabream Rhabdosargus sarba (Forsskål, 1775) from the Arabian Gulf of the United Arab Emirates
}

\author{
Elsayed Farrag*, Ahmed Alzaby, Carter Subbiah \\ Marine Environment Research Department, Ministry of Climate Change and Environment (MOCCaE), Dubai, United Arab Emirates
}

Email address:

eefarrag@moccae.gov.ae (E. Farrag), amalzabi@moccae.gov.ae (A. Alzaby), csubbaih@moccae.gov.ae (C. Subbiah)

${ }^{*}$ Corresponding author

\section{To cite this article:}

Elsayed Farrag, Ahmed Alzaby, Carter Subbiah. Some Biological Aspects and Stock Status of Goldlined Seabream Rhabdosargus sarba (Forsskål, 1775) from the Arabian Gulf of the United Arab Emirates. Computational Biology and Bioinformatics.

Vol. 5, No. 4, 2017, pp. 43-49. doi: 10.11648/j.cbb.20170504.11

Received: December 26, 2016; Accepted: January 6, 2017; Published: November 1, 2017

\begin{abstract}
Evaluation of Rhabdosargus sarba caught from South Arabian Gulf of the United Arab Emirates was investigated using a combination of size frequency and biological data. Forked length ranged between 14.0 and $39.0 \mathrm{~cm}$. Length-weight relationship for combined sexes of $R$. sarba was estimated as $W=0.0338^{*} L^{2.7807}$. The spawning season of $R$. sarba was over a limit time period from November to February and the peaks were in January and February for males and females respectively. The overall sex ratio throughout the study period was 1:1.4 males to females, which was not significantly different from 1:1. The size and age at $50 \%$ sexual maturity was $22.01 \mathrm{~cm} F L$ and 2.39 years. The FiSAT II software was used to perform the estimate of growth, mortality and exploitation rate. Parameter values of asymptotic length $L_{\infty}$ and growth coefficient $K$ were $41.94 \mathrm{~cm} F L$ and $0.25 \mathrm{y}^{-1}$ respectively. Age at length zero $t_{o}$ was estimated by substituting the asymptotic length and growth coefficient in Pauly's equation. Instantaneous rate of total and natural mortalities were estimated as $1.09,0.66 \mathrm{y}^{-1}$ respectively. The length at first capture was obtained as $19.51 \mathrm{~cm}$ that was smaller than the length at first sexual maturity. The rate of fishing mortality $\left(\mathrm{F}=0.43 \mathrm{y}^{-1}\right)$ is higher than the optimum level $\left(\mathrm{F}_{\mathrm{opt}}=0.33 \mathrm{y}^{-1}\right)$ and was close to limit $\left(\mathrm{F}_{\text {limit }}=0.44 \mathrm{yr}^{-1}\right)$ biological reference point, indicated that the resource is slightly over-exploited. Results also indicated that the reduction of current level of fishing mortality to optimum level will lead to reduction of exploitation rate by $23.08 \%$.
\end{abstract}

Keywords: Biological Aspects, Stock Status, Rhabdosargus Sarba, Mortality Rate, Arabian Gulf

\section{Introduction}

Rhabdosargus sarba (Forsskål, 1775) is a fish belonging to family Sparidae, commonly known as seabream that is common in tropical and subtropical inshore waters throughout the Indo-West Pacific including the Red Sea, East Africa, Madagascar, Australia, China and Japan[1, 2]. Fishes of family sparidae are small to medium-sized fishes, diverse in general form, varying in shape from elongate to deepbodies, with a dorsal profile from very steep to gentle sloping. The species of family sparidae are very important commercially and constitute an important part of the artisanal and industrial fisheries [3, 4]. Sparid fishes are an important component of both small-scale fisheries (gill net, trammel net and hand line) and industrial fisheries (trawlers) in the Omani waters of the Arabian Sea [5], whilst hand lining is the main method used to catch $R$. sarba in the southern Arabian Gulf off the coast of the Emirates of Abu Dhabi in the United Arab Emirates [6]. Most Seabream are excellent food fish and are of notable importance to both commercial and recreational fisheries throughout their range $[7,8]$. Despite the importance and widespread occurrence of $R$. sarba, little information about its population biology and stock assessment in the Arabian Gulf and Sea of Oman [5, 6, 9, 10]. In this context, the aim of this study is an attempt to understand various population biology and stock status in order to provide scientific information for management purpose of $R$. sarba in the United Arab Emirates. A 
comparison of the results with the previous studies is also given.

\section{Materials and Methods}

\subsection{Data Collection}

Length frequency data for the present study were collected randomly from five traditional fish-landing sites: Ras AlKheima, Umm Alqwain, Ajman, Sharjah and Abu Dhabi (Fig. 1), during the period from January 2014 to December 2015. Lengths were taken using a measuring board and recorded to the nearest centimeter fork length $F L$. Biological data were collected from specimens purchased from commercial catches during the period from January to December 2014. For each fish total, forked and standard lengths were taken to the nearest $\mathrm{cm}$, while total and gutted weights $(\mathrm{g})$ were taken to the nearest gram. The fish were dissected, sexed and maturity status recorded.

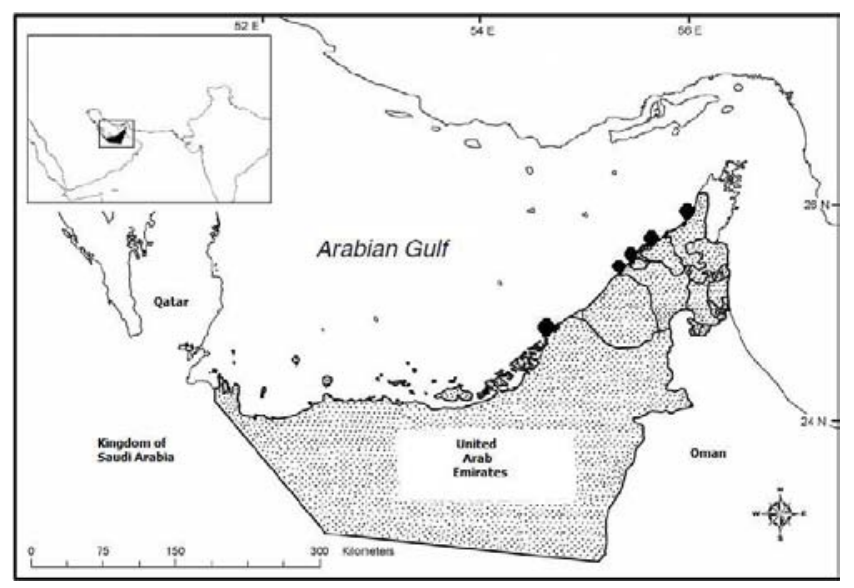

Figure 1. Location of Five landing areas where R. sarba sampled.

\subsection{Length Weight Relationship}

The length weight relationship was estimated with the power equation: $W=a L^{b}$ [11] where $W$ is the weight $g, L$ is the fish total length $\mathrm{cm}, a$ and $b$ are intercept and slope of the relation. The growth type was identified by Student's t-test, which was applied to determine the significance differences between the isometric $b=3$ and allometric $b \neq 3$. The linear equation $F L=a+b^{*} T L$ was utilized for total length-fork length relationship where: $F L$ is the fork length, $T L$ is the total length and $a \& b$ are constants.

\subsection{Reproduction}

Sex was checked by the naked eye and gonads were classified to six stages of maturation according to morphological changes that take place during its development to reach spawning [12]. Maturity stages were classified as: immature, resting stage, maturing, mature, ripe and spent. Gonads weight was measured to the nearest $0.01 \mathrm{~g}$. Gonado-somatic index GSI was calculated monthly for both males and females of $R$. sarba by the following equation: $G S I=W_{G} / W_{g} * 100$ [13] where: $W_{G}$ is the fish gonad weight and $W_{g}$ is the fish gutted weight. The population sexual structure was examined using Chi-Square $X^{2}$ goodness of fit tests. Independent tests were conducted to determine whether sex ratio differed significantly from $1: 1$. The probability level was set at 0.05 . The mean size at first maturity $L_{50}$ was estimated by fitting the logistic function to the proportion of mature fish in $1.0 \mathrm{~cm} T L$ size categories and determined as the size at which $50 \%$ of individuals were mature [14] $P=1 /(1+\exp (-r(L-L m)))$ where: $P$ is the proportion of sexually mature individuals by length $L$ and $r$ is the slope of the curve.

\subsection{Growth Estimation}

Length frequency data were pooled into groups with $10 \mathrm{~mm}$ length intervals. Growth was investigated by fitting the von Bertalanffy growth function to length frequency data. The von Bertalanffy growth equation is defined as follows: $L_{t}=L_{\infty} * 1-\exp ^{-K^{*}(t-t)}[15]$ Where $L_{t}$ is the length at time $t, L_{\infty}$ is the asymptotic length, $K$ is the growth coefficient and $t_{0}$ is the hypothetical time at which length is equal to zero. Estimation of an initial value for asymptotic length $L_{\infty}$ and $Z / K \quad(Z=$ total mortality and $K=$ growth coefficient) using $[16,17]$ methods. The electronic length frequency analysis method ELEFAN I [18] was used to fit von Bertalanffy growth function $V B G F$ [19]. Whilst the age at length zero $t_{o}$ was estimated by employing the equation of $\log \left(-t_{0}\right)=-0.3922$ $0.2752 \log L_{\infty}-1.038 \log K$ [20]. Longevity was obtained according to the equation: $t_{\max }=3 / K$ [21] where: $t_{\max }$ is the maximum age the fish of a given population would reach and $K$ is the curvature parameter. To compare the estimated growth parameters of the present work with the other studies, the growth performance index, $\phi^{\prime}$ [22] was calculated according to the equations: $\phi^{\prime}=\log K+2 \log L_{\infty}$ and $\phi=\log K+2 / 3 \log W_{\infty}$ for length and weight respectively.

\subsection{Mortalities}

Total instantaneous mortality rate $Z$ was calculated using the length converted catch curve developed from length frequency distribution [23, 24]. Natural instantaneous mortality $M$ was estimated using the empirical formula of Pauly [20] as follows; $L_{n}(M)=-0.152-0.279 L_{n}\left(L_{\infty}\right)+0.6543$ $L_{n}(K)+0.463 \operatorname{Ln}(T)$ where $L_{\infty}$ and $K$ are $V B G F$ parameters and $T$ is the mean annual temperature, which was considered in this study $27.5^{\circ} \mathrm{C}$. The annual instantaneous rate of fishing mortality was obtained by subtracting the natural mortality rate $M$ from the total mortality rate $Z$ derived from length converted catch curve $F=Z-M$. The histogram showing probability of capture for each size class was estimated by backward extrapolation of the straight portion of the right descending part of the catch curve. The existing exploitation rate $E$ was estimated as the proportion of the fishing mortality relative to total mortality $E=F / Z$.

Resource status was evaluated by comparing estimates of the fishing mortality rate with target $F_{\text {opt }}$ and limit $F_{\text {limit }}$ 
biological reference points which were defined as: $F_{\text {opt }}=0.5 \mathrm{M}$ and $F_{\text {limit }}=2 / 3 M[25]$.

\section{Results}

\subsection{Length-Weight Relationship}

The linear regression analysis of the length-weight data allowed the estimation of the constants $a$ and $b$ of the length-

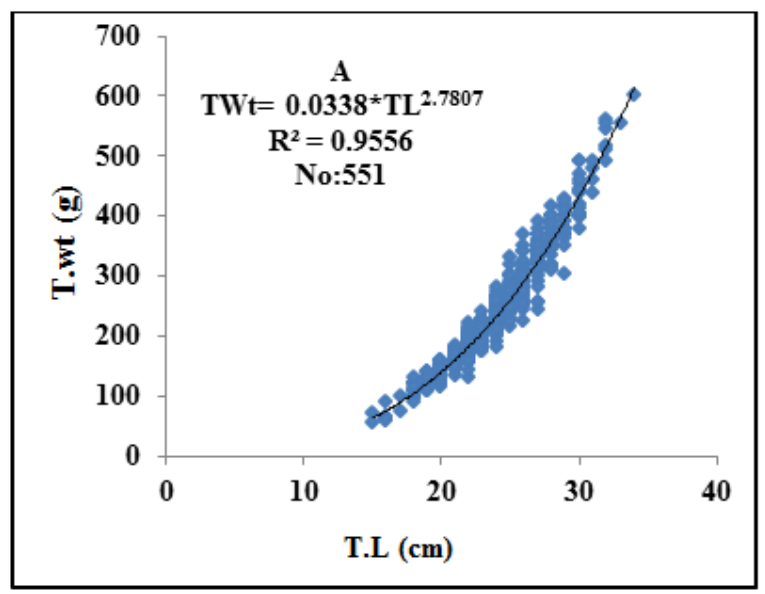

Figure 2. Length-weight (A) and length-length (B) relationship of R. sarba collected from southern Arabian Gulf of the UAE.

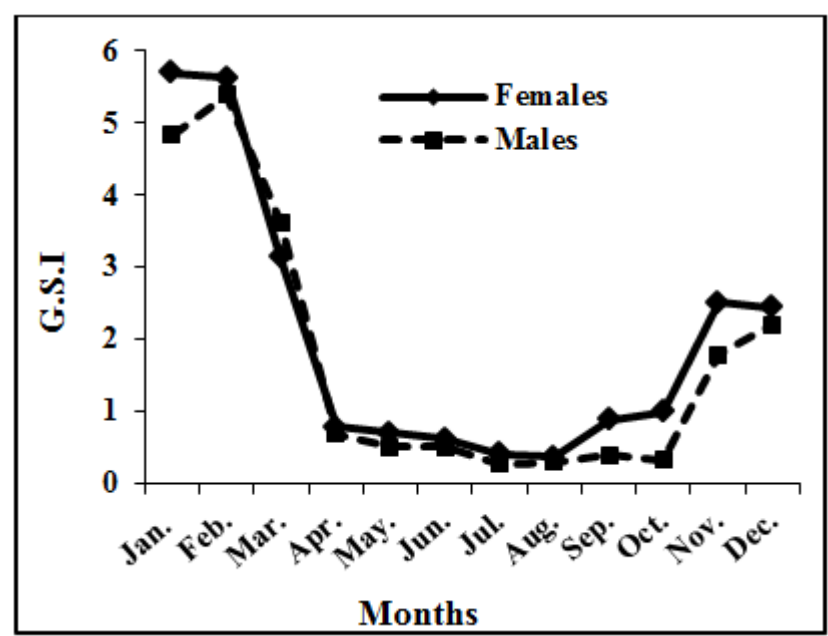

Figure 3. Monthly variations of GSI for R. sarba from southern Arabian Gulf of the UAE.

\subsection{Reproduction}

Out of 551 specimens examined 258 (43.94\%) were males and 293 (93.94\%) were females, giving a sex ratio of 1: 1.4 . The sex ratio not showed a statistically significant deference from the $1: 1\left(X^{2}=68.8 ; P>0.05\right)$. The gonado-somatic index GSI ranged in the females from 0.36 to 5.69 with a mean of $2.01 \pm 1.93$, while in males the values of GSI ranged from 0.27 to 5.40 with a mean of $1.74 \pm 1.88$. Fig. 3 shows the monthly changes in gonado-somatic index by sex. For both sexes, GSI started to increase from November (2.51 and 1.79 for females and males respectively), and maintained in high values up to February (5.62 and 5.40 for females and males respectively), then dropped in March. Therefore, the weight relationship represented by the equation $W=$ $0.0338 T L^{2.7809}$ or $\log \mathrm{W}=-1.4712+2.7807 \log L$ with a regression coefficient $R^{2}=0.96$. The $b$ value showed a significant difference in isometric growth $\left(95 \% \mathrm{CI}_{b}=2.26\right.$ 2.36, t-test, $P<0.05)$. The t-test result shows that negative allometric growth was observed for $R$. sarba. The total length and fork length relationship was expressed as: $F L=0.8696 T L+0.6221\left(R^{2}=0.97\right)$. Fig. 2 .

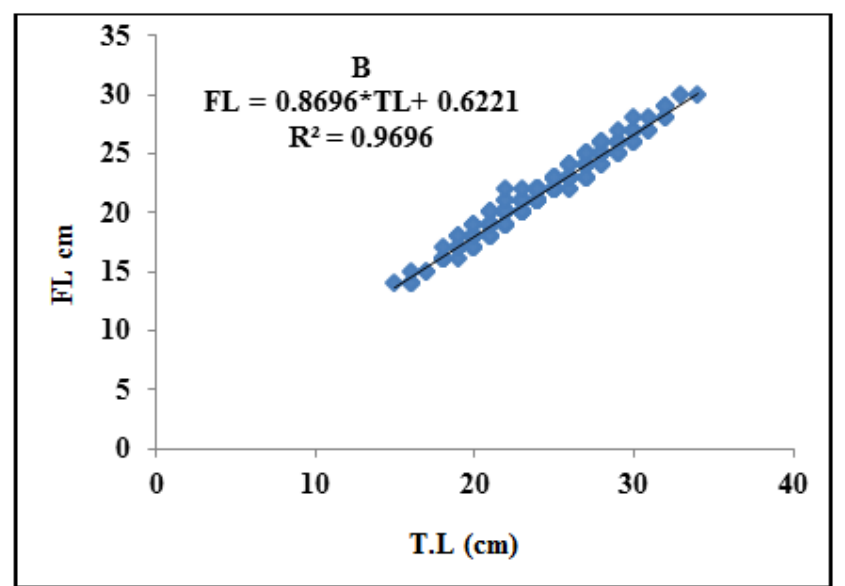

spawning season was considered to be from November to March, with a peak occurring during January and February for females and males respectively. The proportion of fish in aggregated size frequency samples that were below the mean size at first sexual maturity (juvenile retention rate) was $26.13 \%$. The mean length $\mathrm{L}_{\mathrm{m}}$ and age $T_{m}$ at first sexual maturity for $R$. sarba was estimated as $24.6 \mathrm{~cm}$ TL $(22.01 \mathrm{~cm}$ FL) and 2.95years. Fig. 4.

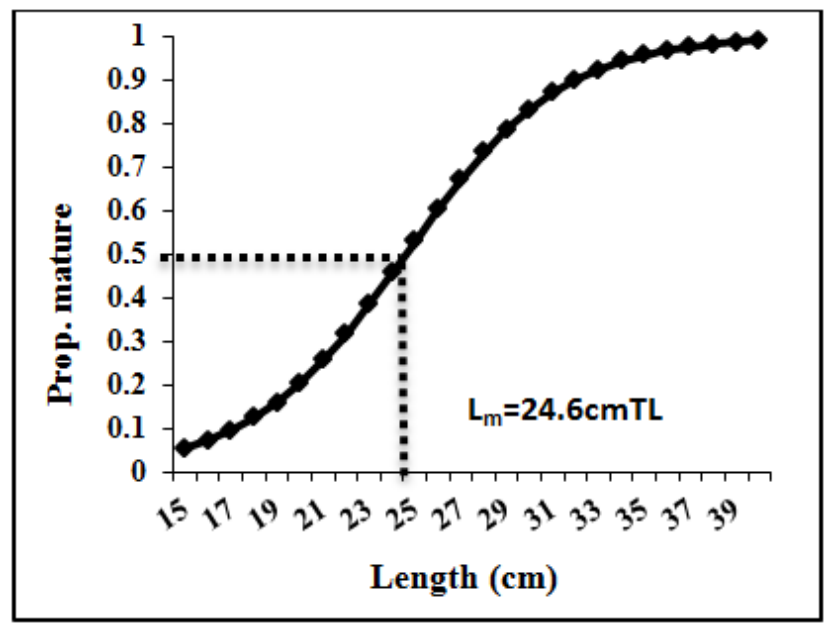

Figure 4. Estimation of Length at first maturity Lm of R. sarba.

\subsection{Growth Parameters}

A total of 5085 specimens were collected from fish ranging in size from 14.0 to $39.0 \mathrm{~cm} F L$ during the period from January 2014 to December 2015. The mean fork length was estimated $26.5 \pm 7.65 \mathrm{~cm}( \pm \mathrm{SD})$, with the highest 
frequency in length group $20.0 \mathrm{~cm}(11.66 \%)$. On the other hand the terminal length groups 14.0 and $39.0 \mathrm{~cm}$ were lowest frequency and contributed with $0.12 \%$ and $0.02 \%$ respectively. Fig. 5

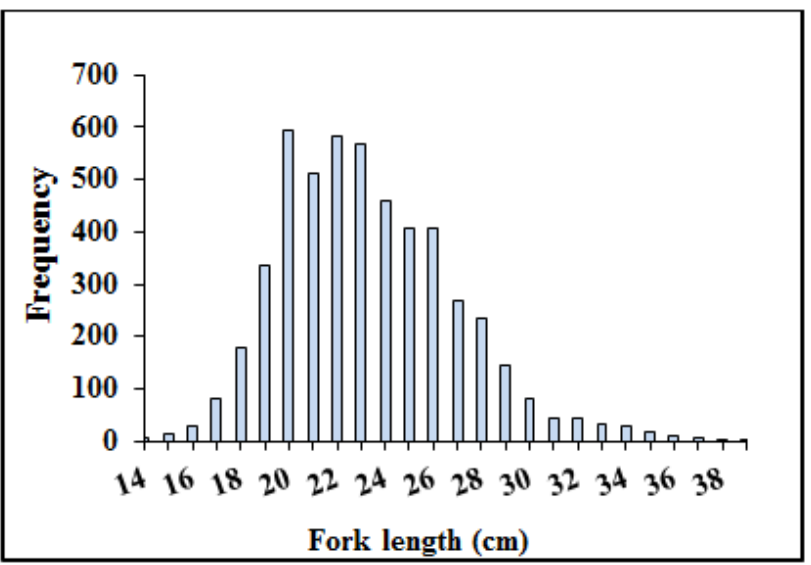

Figure 5. Length frequency distribution of $R$. sarba in the Arabian Gulf of the UAE.

The analysis of length frequency data by the Powellwetherall method Fig. 6 . gave the initial estimate of $L_{\infty}$ value of $41.94 \mathrm{~cm}$ and $\mathrm{Z} / \mathrm{K}$ value of 4.694

The Optimized values of $\mathrm{L}_{\infty}$ and $\mathrm{K}$ obtained by ELEFAN II were $41.94 \mathrm{~cm}$ and $0.25 \mathrm{y}^{-1}$ respectively. The goodness fit of
$R_{n}$ for the estimated $L_{\infty}$ and $k$ values was 0.201 , and the oscillation parameters $\mathrm{C}$ and WP were assumed to be 0 as it is a tropical species. The non seasonalized restricted length frequency histogram with growth curve is shown in Fig. 7. The estimated $t_{o}$ value was $-0.58 \mathrm{y}^{-1}$ and the von Bertalanffy growth equation for $R$. sarba can be written as $\mathrm{L}_{\mathrm{t}}=41.94 * 1-$ $\exp ^{-0.25^{*}(t+0.58)}$. The values of growth performance index for length and weight were estimated as 2.64 and 1.43 respectively. The life span of $R$. sarba in its natural habitat was computed around 12.0 years.

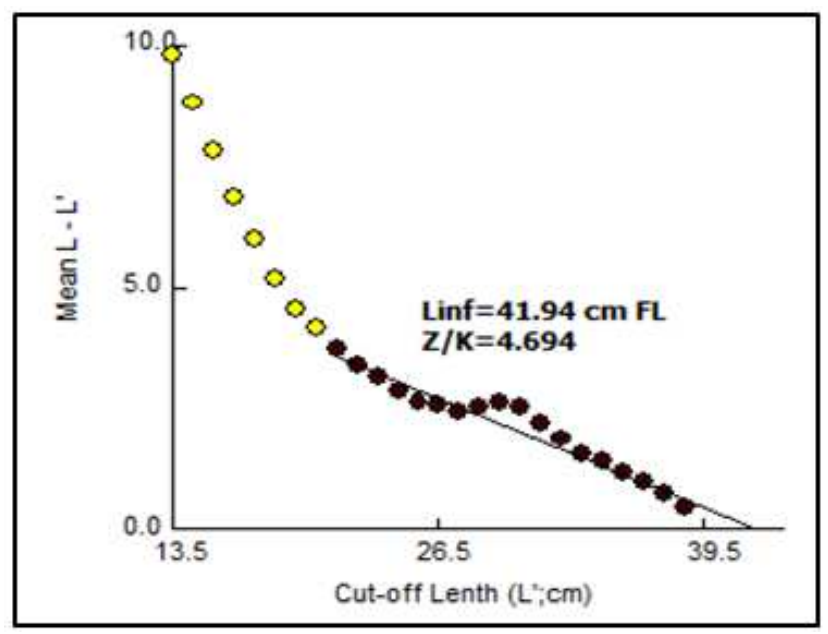

Figure 6. Powell-Wetherall plot of R. sarba.

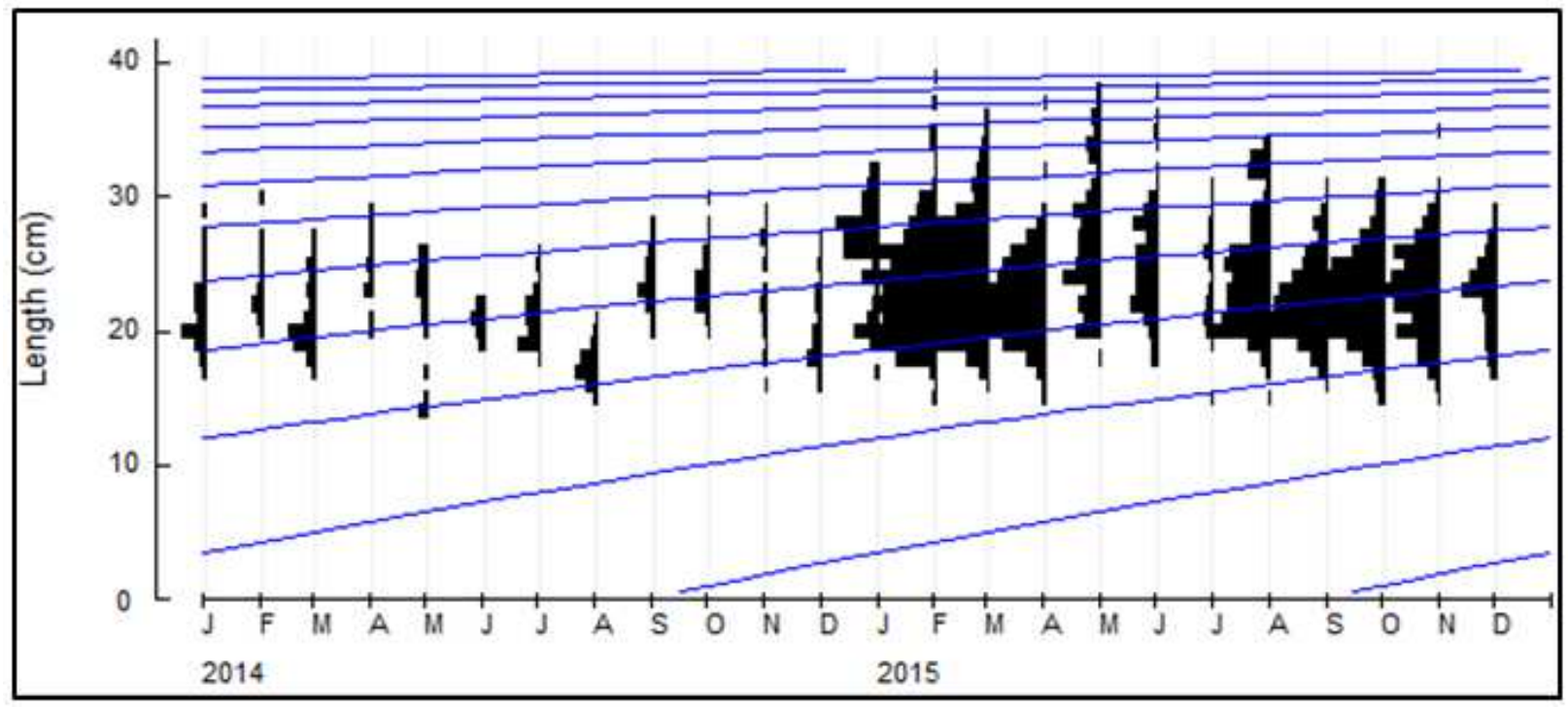

Figure 7. Monthly length frequency data and growth curve of R. sarba drawn using ELEFAN I.

\subsection{Mortality and Assessment}

The annual instantaneous rate of total mortality $Z$ derived from length converted catch curve (Fig.8) was $1.09 \mathrm{y}^{-1}(95 \%$ confidence interval of $\mathrm{Z}=-1.15-(-1.03) ; \pm \mathrm{SD}$ of the slope $=0.029: \mathrm{r}=-0.99$. The length at first capture $\mathrm{L}_{\mathrm{c}}$ (length at $50 \%$ capture) was estimated as $19.51 \mathrm{~cm} \mathrm{FL,} \mathrm{which} \mathrm{was}$ considerably smaller than the mean size at which first sexual maturity was attained $\left(L_{m}=22.01 \mathrm{cmFL}\right)$. Fig. 9 .

The natural mortality coefficient $M$ obtained through Pauly empirical formula at $27.5^{\circ} \mathrm{C}$ temperature was $0.66 \mathrm{y}^{-1}$. Therefore, the computed instantaneous fishing mortality coefficient $\left(F=0.43 y^{-1}\right)$ was considerably greater than the target $\left(F_{\text {opt }}=0.33 y^{-1}\right)$ and close to limit $\left(F_{\text {limit }}=0.44\right)$ biological reference point, indicating that the stock is slightly overexploited. The recruitment pattern graph showed that $R$. sarba have highest recruitment during the period from April to June. The respective current of exploitation ratio $E$ was 0.39 ; the exploitation level which maintains the spawning stock biomass at $50 \%$ of the virgin spawning biomass, $E_{0.5}$ 
was estimated as 0.36 . The results indicated that reducing the current fishing effort to the target reference point will lead to reducing in exploitation ratio by $23.08 \%$.

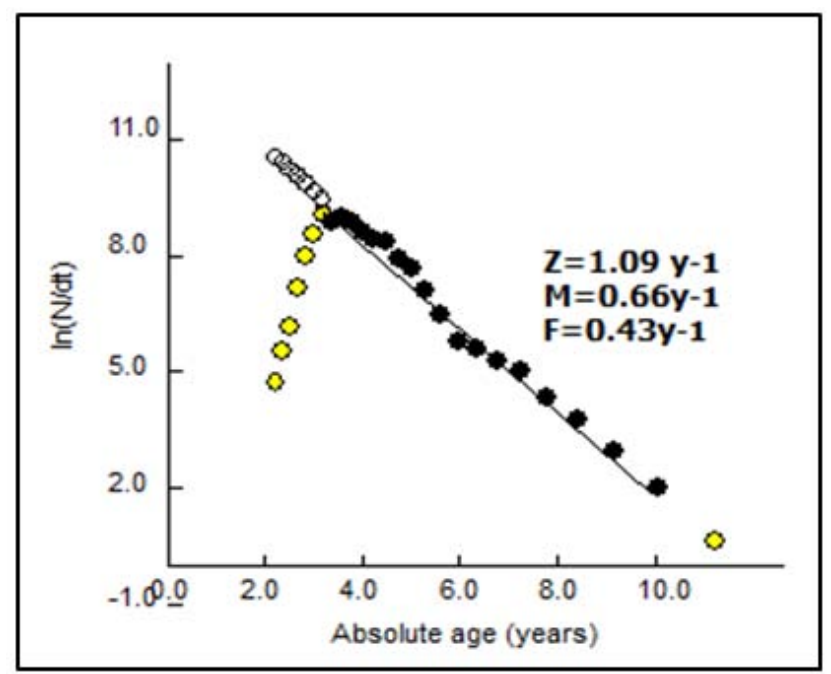

Figure 8. Length converted catch curve of $R$. sarba $L_{\infty}=41.94 \mathrm{~cm}, K=0.25 y^{-1}$.

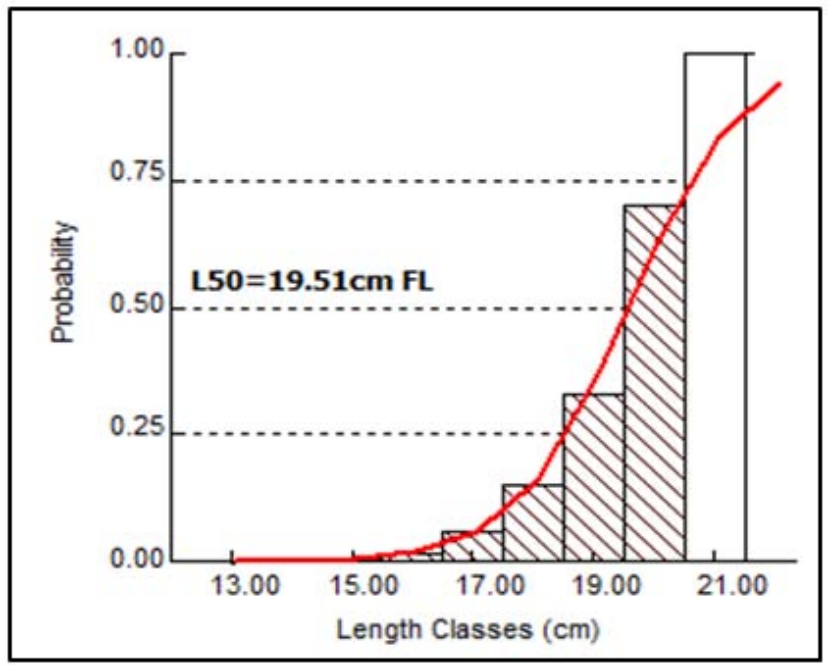

Figure 9. Probability plot of $R$. sarba showing the mean size at capture $19.51 \mathrm{~cm}$.

\section{Discussion}

The length- weight relationship $L W R$ is considered as the building blocks of the stock assessment and population structure. The estimated $b$ value by the non-linear regression analysis of the length-weight relationship was significantly below 3, which shows that the fish exhibits allometric growth. The $L W R$ observed during the present study was $\mathrm{W}=0.0338 * \mathrm{~L}^{2.7}$ and The $b$ parameter value is less than that the value obtained by [6] from the Coast of Emirate AbuDhabi $(b=2.94)$ and [5] from the Oman Coast of the Arabian Sea $(\mathrm{b}=2.85)$. The value of $a$ and $b$ differ not only in different species but in the same species depending on sex, maturity stage, feeding intensity, etc. [26].

Overall males to female's ratio were $1: 1.4$. This ratio did not differ significantly from 1:1. The results also revealed that, during the periods from April to September males to females' ratio was $1: 2.6$ and the ratio was statistically differing from 1 to 1 expected ratio at $95 \%$ confidence level. The obtained results are compatible with the results obtained by [10] from Omani water of the Arabian Sea. She stated that males to female's ratio were 1:0.91. This ratio did not differ significantly from 1:1 ratio.

Monthly variation in GSI of $R$. sarba from the southern part of the Arabian Gulf of the UAE was evaluated. The maximum values of the GSI were recorded 5.40 and 5.69 for males and females, respectively. For $R$. sarba, the spawning seasons were identified during the winter season. The results are consistent with the findings of the previous study in Omani waters [27, 10]. They found that the peak of the reproductive season in January and February for males and females respectively. On the other hand the spawning season of $R$. sarba in the Emirates of Abu Dhabi was identified during the winter season [6].

From the maturation curve, the length at first sexual maturity of $R$. sarba was $24.6 \mathrm{~cm}$ TL which corresponding to 2.95years. The study also revealed that a considerable proportion $26.13 \%$ of $R$. sarba catch didn't reach to the first sexual maturity. Therefore, in order to protect this species and to enable it to share at least for one time in reproduction, the mesh sizes must be re-evaluated. The present results are more or less similar to the previous ones. Wallace [28] calculated the length at maturity of $R$. sarba in Lake St. Lucia to be $26.0 \mathrm{~cm}$ TL which corresponding to an age of 1.8 years. El-Agamy [9] found that R. sarba in the Arabian Gulf mature between their second and third year of life. Age at maturity of $R$. sarba was therefore estimated from the growth curve to be 1.8years in South Africa [29]. Grandcourt [6] declared that the length at first sexual maturity of $R$. sarba was $23.5 \mathrm{~cm} F L$ (2.0years) and $23.7 \mathrm{~cm} F L$ (2.1years) for males and females respectively. On the other hand, in Omani waters of the Arabian Sea the length at first sexual maturity was 29.6 and $28.9 \mathrm{~cm}$ TL for males and females, respectively and these lengths lies in age group II [10].

The values of $L_{\infty}$ and $K$ for both sexes of $R$. sarba were calculated as $41.94 \mathrm{~cm}$ and $0.25 \mathrm{y}^{-1}$ using ELEFAN $I$ and Powell-Wetherall plot. The growth performance index $\phi^{\prime}$ was estimated as 2.64. The age and growth of Sparus sarba from the Arabian Gulf based on scales readings were estimated by [9]. He evaluated the growth parameters as $\mathrm{L}_{\infty}=37.5 \mathrm{~cm} \mathrm{TL}$ and $\mathrm{K}=0.16 \mathrm{y}^{-1}$, the $\mathrm{K}$-value suggests that Arabian Gulf population has a lower growth rate but attains a smaller maximum size and larger age. Radebe [29] gave the growth parameters of $R$. sarba in South Africa as: $\mathrm{L}_{\infty}=71.5 \mathrm{~cm}$ FL, $\mathrm{K}=0.16 \mathrm{y}^{-1}$ and $\mathrm{t}_{\mathrm{o}}=-0.996$ year. Hughes [30] found that for both sexes of $R$. sarba in south-eastern Australia, the growth parameters were: $\mathrm{L}_{\infty}=26.40 \pm 0.40 \mathrm{~cm} F L, \mathrm{~K}=0.39 \pm 0.02 \mathrm{y}^{-1}$ and $t_{\mathrm{o}}=-0.56 \pm 0.09$ years. Grandcourt [6] stated the growth parameters of both sexes of $R$. sarba in Emirates Abu-Dhabi as $\mathrm{L}_{\infty}=25.3 \mathrm{~cm} F L, \mathrm{~K}=1.29 \mathrm{y}^{-1}$ and $\mathrm{t}_{\mathrm{o}}=-0.03$ year. On the other hand the growth parameters were estimated by [5] in Omani waters of the Arabian sea as $\mathrm{L}_{\infty}=46.97 \mathrm{~cm} T L, \mathrm{~K}=0.33 \mathrm{y}^{-1}$ and $\mathrm{t}_{\mathrm{o}}=0.83$ year. These variations in population parameters can be 
attributed to different condition e.g sample size, sexes and maturation.

The length at first capture (the length at which $50 \%$ of the fish at that size are vulnerable to capture) was estimated as $19.51 \mathrm{~cm} \mathrm{FL}$. This value is equivalent to an age of 1.92 years and it was smaller than the length at first maturity $\mathrm{L} m=22.01 \mathrm{~cm} F L$ i.e., these fishes are captured before their first spawning period. Grandcourt [6] stated the length and age at first capture as $14.0 \mathrm{~cm} F L$ and 0.59 years in Emirates of Abu Dhabi. Whilst Mehanna [10] from Omani waters of the Arabian Sea estimated the length and age at first capture as $22.9 \mathrm{~cm} T L$ and 1.2 years.

Total, natural and fishing mortalities were estimated as: $1.09,0.66$ and $0.43 \mathrm{y}^{-1}$. The obtained results of mortalities are more or less those results estimated by different authors in different areas. Grandcourt [6] mentioned the total, natural and fishing mortalities are: $1.04,0.26$ and $0.77 \mathrm{y}^{-1}$. Mehanna [5] estimated the total, natural and fishing mortalities are: $1.80,0.60$ and $1.20 \mathrm{y}^{-1}$. The specified precautionary target $\mathrm{F}_{\text {opt }}=0.5 \mathrm{M}$ and limit $\mathrm{F}_{\text {limit }}=2 / 3 \mathrm{M}$ values are considered to be appropriate biological reference points, in particular given current management objectives which are aimed at stock re-building and resource conservation. The current fishing mortality rate $\mathrm{F}=0.43 \mathrm{y}^{-1}$ was relatively greater than the target $\left(\mathrm{F}_{\mathrm{opt}}=0.33 \mathrm{y}^{-1}\right)$ and almost equal to limit $\left(\mathrm{F}_{\text {limit }}=0.43 \mathrm{y}^{-1}\right)$ biological reference points. The results also revealed that, reducing of the current fishing level $0.43 \mathrm{y}^{-1}$ to optimum level 0.33 will lead to reducing of exploitation rate by $23.08 \%$.

\section{Conclusion}

This paper provides information on biology and stock status of one of the key species in the United Arab Emirates $R$. sarba locally called (Gabit). This investigation could strongly helpful to the researcher and policy maker for the preparation of very effective sustainable management plans of fishery resources of the United Arab Emirates. From the present study it is evident that the spawning season of $R$. sarba during the period from November to March and the length at first sexual maturity was $22.01 \mathrm{~cm}$. Thus, it is necessary to reduce fishing pressure on this species during the spawning season. The results also revealed that the length at capture is smaller than the length at first maturity, so we can say that the fish must be caught at least at $23.0 \mathrm{~cm}$ FL to get the chance to spawn even once. The results also concluded that the current fishing mortality is higher than the optimum and the present level of exploitation rate $(\mathrm{E}=0.39)$ was higher than the exploitation rate $\left(\mathrm{E}_{0.5}=0.36\right)$ which maintains $50 \%$ of the stock biomass as spawning stock $\mathrm{F}_{\text {opt }}=0.33$.

\section{Acknowledgements}

The authors are grateful to Ministry of Climate Change and Environment, Dubai, UAE for moral and financial assistance. We would like to thank Mr. Ahmed Al-Zaaby, the Chairman of Marine Environment Research Department for his support, and thanks a lot to all colleagues for cooperation to completion this work. This work is part of the activity (Stock assessment of the key species in the United Arab Emirates).

\section{References}

[1] W. Fisher and G. Bianchi, (Eds.), "FAO Species Identification Sheets for Fishery Purposes. Western Indian Ocean (Fishing areas 51)" FAO, Rome, IV. 1984.

[2] M. M. Smith and P. C. Heemstra, "Tetraodontidae. In: Smith MM, Heemstra PC (eds), Smiths' sea fishes. Springer Verlag, Berlin, pp 894-903, http://dx.doi.org/10.1007/978-3- 64282858-4, 1986.

[3] J. M. Al Mamry, I. D. Mc-Carthy, C. A. Richardson and S. B. Meriem, "Biology of the king soldier bream (Argyrops spinifer, Forsskål 1775; Sparidae), from the Arabian Sea, Oman” Journal of Applied Ichthyology. 25: 559-564, 2009.

[4] P. J. Siddiqui, S. A. Amir, and R. Masroor, "The sparid fishes of Pakistan, with new distribution records" Zootaxa 3857; (1): 71-100. 2014.

[5] S. F. Mehanna, F. R. Al-Kiyumi and L. Al-Kharousi, "Reproductive dynamics of the goldlined seabream Rhabdosargus sarba (Forsskal, 1775) from the Arabian Sea coast of Oman" International Journal of Agri. Science, 2 (4): 365-373, 2012.

[6] E. Grandcourt, T. Z. Al Abdessalaam, F. Francis and A. Al Shamsi, "Demographic parameters and status assessments of Lutjanus ehrenbergii, Lethrinus lentjan, Plectorhinchus sordidus and Rhabdosargus sarba in the southern Arabian Gulf” J. Appl. Ichthyol. 1-9. 2011.

[7] M. J. Smale and C. D. Buxton, "Aspects of the recreational ski-boat fishery off the Eastern Cape, South Africa" S. Afr. J. mar. Sci. 3: 131-144. 1985.

[8] C. Sommer, W. Schneider and J. M. Poutiers, "FAO species identification field guide for fishery purposes. The living marine resources of Somalia” FAO, Rome, 376 pp. 1996.

[9] A. E. El-Agamy, "Biology of Sparus sarba Forskål from the Qatari water, Arabian Gulf" J Mar Biol Assoc India 31: 129-137, 1989.

[10] S. F. Mehanna, F. R. Al-Kiyumi, and L. Al-Kharousi, "Population Dynamics and Management of Goldlined Seabream Rhabdosargus sarba (Sparidae) from the Oman Coast of Arabian Sea" Fisheries and Aquaculture Journal, 40: $1-9,2012$.

[11] W. E. Ricker, "Computation and interpretation of biological statistics of fish populations" Bulletin of the Fisheries Research Board of Canada, 191: 382 pp. 1975.

[12] G. V. Nikolsky, "The ecology of fishes. Academy Press, London and New York" xv 352 pp. 1963.

[13] M. R. Claereboudt, J. L. McIlwain, H. S. Al-Oufi and A. A. Abu-Ali, "Patterns of reproduction and spawning of the kingfish (Scomberomorus commerson, Lac'ep'ede) in the coastal waters of the Sultanate of Oman" Department of Marine Science and Fisheries, College of Agricultural and Marine Sciences. Fisheries Research No (73): 273-282, 2005. 
[14] M. King, "Fisheries biology, Assessment and management" Oxford, UK, Fishing News Books. Blackwell Science Ltd. 342P. 2005.

[15] P. Sparre and S. C. Venema, "Introduction to tropical fish stock assessment" FAO Fisheries technical paper, Roma, 450pp. 1998.

[16] D. G. Powell, "Estimation of mortality and growth parameters from the length frequency of a catch" Rapp. P.-v. Reun. CIEM, 175: 167-169, 1979.

[17] J. A. Wetherall, "A new method for estimating growth and mortality parameters from length frequency data" ICLARM Fishbyte, 4 (1): 12-14, 1986.

[18] D. Pauly, "A review of the ELEFAN system for analysis of length frequency data in fish and invertebrates. p. 7-34. D Pauly and GR Morgan (eds.), In: Length-based Methods in Fisheries Research" ICLARM Conference Proceedings 13. ICLARM, Manila. 1987.

[19] L. von Bertalanffy, "A quantitative theory of organic growth (Inquiries on growth laws. 2)" Human Biology, 10: 181-213, 1938.

[20] D. Pauly, "On the interrelationships between natural mortality, growth parameters and mean environmental temperature in 175 fish stocks" Journal du Conseil International pour l'Exploration de la Mer, 39: 175-199, 1980.

[21] D. Pauly, "The relationships between gill surface area and growth performance in fish: a generalization of von Bertalanffy's theory of growth" Berichte der Deutschen Wissenschaftlichen Kommission für Meeresforschung 28 (4): 251-282, 1981.
[22] D. Pauly, J. L. Munro, "Once more on the comparison of growth in fish and invertebrates" ICLARM Fishbyte, 2 (1): 21, 1984.

[23] D. Pauly, "Length-converted catch curves and the seasonal growth of fishes" Fishbyte 8: 33-38, 1990.

[24] F. C. Gayanilo, P. Sparre, and D. Pauly, "The FAO ICLARM Stock assessment Tools FiSAT, users guide. FAO Computerized Information Series (Fiheries)" No.8. ROME, FAO. 126p. 1996.

[25] K. Patterson, "Fisheries for small pelagic species: an empirical approach to management targets. Reviews in Fish Biology and Fisheries" 2: 321-338, 1992.

[26] S. P. Biswas, "Manual of methods in fish biology" South Asian publishers. P.157, 1993.

[27] F. S. Ibrahim, J. S. Goddard, A. Abu Ali and K. J. Rana, “A histological study of maturity in male goldlined seabream Rhabdosargus sarba (Forskål, 1775) in the Oman Sea "Journal of Applied Ichthyology 26 (6): 892-897, 2010.

[28] J. H. Wallace, "The estuarine fishes of the east coast of South Africa: III. Reproduction" Invest Rep Oceanogr. Res. Inst. Durban 41: 1-51, 1975.

[29] P. V. Radebe, B. Q. Mann, L. E. Beckley, and A. Govender, "Age and growth of Rhabdosargus sarba (Pisces: Sparidae) from KwaZulu-Natal, South Africa" Fisheries Research, 58: 193-201. 2002.

[30] J. M. Hughes, J. Stewart and B. W. Kendall, "Growth and reproductive biology of tarwhine Rhabdosargus sarba (Sparidae) in eastern Australia" Marine and Freshwater Research, 59 (12): 1111-1123. 2008. 